\title{
Design and Analytical Calculations of Double Wishbone for Formula Student Race Car
}

\author{
Suyash Yashwant Wagh \\ B.E. Mechanical Engineer \\ JSPM's Rajarshi Shahu College of Engineering \\ Pune, India
}

\author{
Eshita Amal Nandi \\ Pursuing B.E. in Mechanical Engineering \\ JSPM's Rajarshi Shahu College of Engineering \\ Pune, India
}

\begin{abstract}
The functional objective of the suspension system is to provide relative motion between the sprung and the unsprung mass. This is achieved by a spring to absorb the shocks and some kinematic linkages holding them together with particular degrees of freedom. Further for better handling the kinematics of the system is designed and optimized. This research focuses on the simulation, design, and analytical calculations of the kinematical linkage called A-arm. The double-wishbone suspension geometry was analyzed in Lotus Shark software to procure the most appropriate location of the hardpoints. A-arm was modeled in CATIA V5, Autodesk Fusion 360, and analyzed in ANSYS 16.0. Software results are correlated with the analytical calculations to obtain a feasible solution.
\end{abstract}

Keywords-Double wishbone, A-arm, thickness calculation, rod end selection, vehicle dynamics, threaded joints, etc.

\section{INTRODUCTION}

The FS car's suspension controls the angle, position, and velocity of each wheel to maintain a high value of mechanical grip while transmitting the forces generated by tires to the chassis. A reliable method to determine the forces produced by the road loads in suspension members opted. In this paper, a detailed analytical calculation was explained for deciding the A-arm diameter using a set of calculations. The component is designed to be costeffective, durable, and lightweight. As the double-wishbone undergoes tension and compression forces, the yield and buckling need to be calculated, followed by the threaded joints calculation for the rod ends as the force being transmitted through these to the chassis.

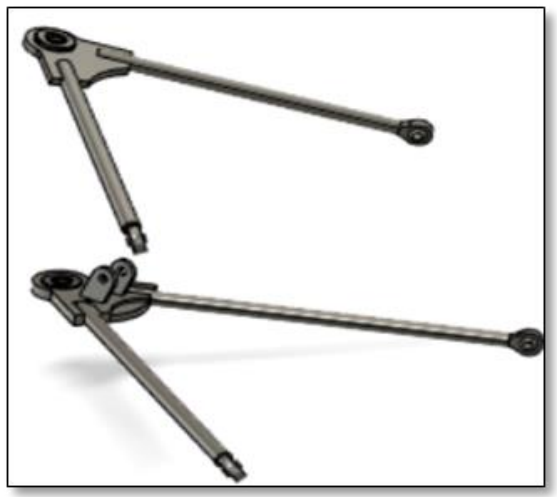

Fig1. Double wishbone

\section{PROBLEM STATEMENT}

The double-wishbone suspension system is independent. This design allows the race car engineers to control the wheel's motion throughout suspension travel, controlling the parameters such as camber angle, caster angle, toe, roll center height, and scrub radius.

They are a force transmitting and kinematic part, so dynamic stability is the most crucial factor. Designing by using lightweight material along with it being cost-efficient is the recent discovery many teams are trying to develop. In the era of upgrading trends, many teams are trying to evolve in a world full of research related to advanced materials.

In this fast-changing and technologically developed world, there is much-advanced software in use, but all that software is programmed on the necessary calculations. To correlate those results with calculations and further substantiate those software results, we need analytical calculation. Because sometimes that software is constrained to some limits. The paper explains the method to find the thickness of the a-arm by pen and paper calculation. These calculations require critical skill, and also, they are an essential set for sound stress engineers in the automobile industry.

Some teams want better design irrespective of cost, and some want a mediocre design with the economical product. But many teams are trying to get the intermediate between them, so to improve this, we need our work to be well developed from all angles and aspects. Hence analytical form is considered to be more cogent.

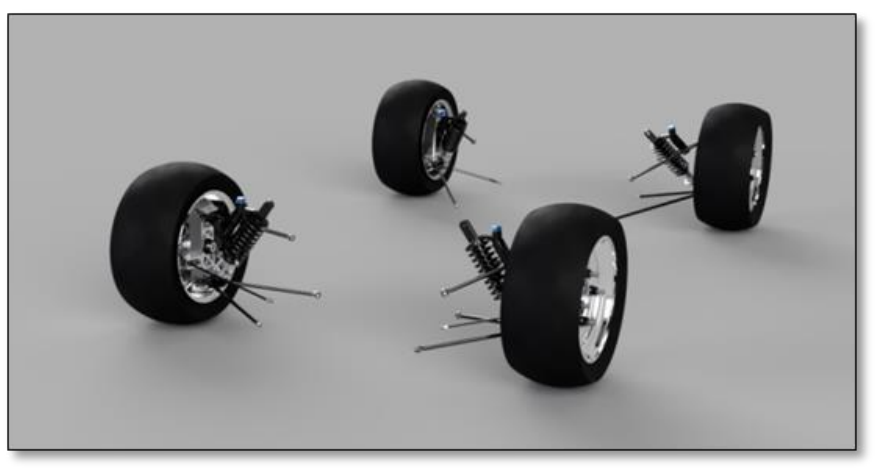

Fig2. Suspension Assembly 


\section{OBJECTIVES}

1. A lot of forces during cornering, acceleration, and bump are applied directly during dynamic conditions, so it is essential to produce a compact, lightweight, and reliable suspension system to increase vehicle performance.

2 . To reduce the unsprung mass.

3. Combining analytical calculations result with FEA as it provides a good starting point for the design.

4. To understand how much an advantage FEA gives during the design process, it's first necessary to understand how analysis and design optimization are performed without FEA.

5. To determine loads, restraints, and material properties, pen and paper calculations played a vital role.

6 . The FEA result's verification and validation with an independent set of calculations are crucial to provide confidence in the analysis results.

\section{ABBREVIATIONS}

$\begin{array}{ll}\text { Abbreviations } & \text { Explanation } \\ \mathrm{Ax} & \text { Acceleration along X-axis } \\ \mathrm{Ay} & \text { Acceleration along Y-axis } \\ \mathrm{W}_{\mathrm{f}} & \text { Weight on front } \\ \mathrm{W}_{\mathrm{r}} & \text { Weight on rear } \\ \mathrm{H}_{\mathrm{CG}} & \text { CG height to the ground } \\ \mathrm{W}_{\text {Longitudinal }} & \text { Longitudinal load transfer on a wheel } \\ \mathrm{W}_{\mathrm{Lateral}} & \text { Lateral load transfer on a wheel } \\ \mathrm{FOS} & \text { Factor Of Safety } \\ \mathrm{P}_{\mathrm{act}} & \text { Actual Load } \\ \mathrm{P}_{\mathrm{cr}} & \text { Critical Load } \\ \mathrm{E} & \text { Modulus of elasticity } \\ \mathrm{d}_{\mathrm{c}} & \text { Core Diameter } \\ \mathrm{d} & \text { Nominal Diameter } \\ \mathrm{d}_{\mathrm{i}} & \text { Inner diameter } \\ \mathrm{d}_{\mathrm{o}} & \text { Outer diameter } \\ \sigma_{t} & \text { Maximum tensile stress } \\ \mathrm{KL} & \text { Equivalent length of column end } \\ \end{array}$

\section{METHODOLOGY}

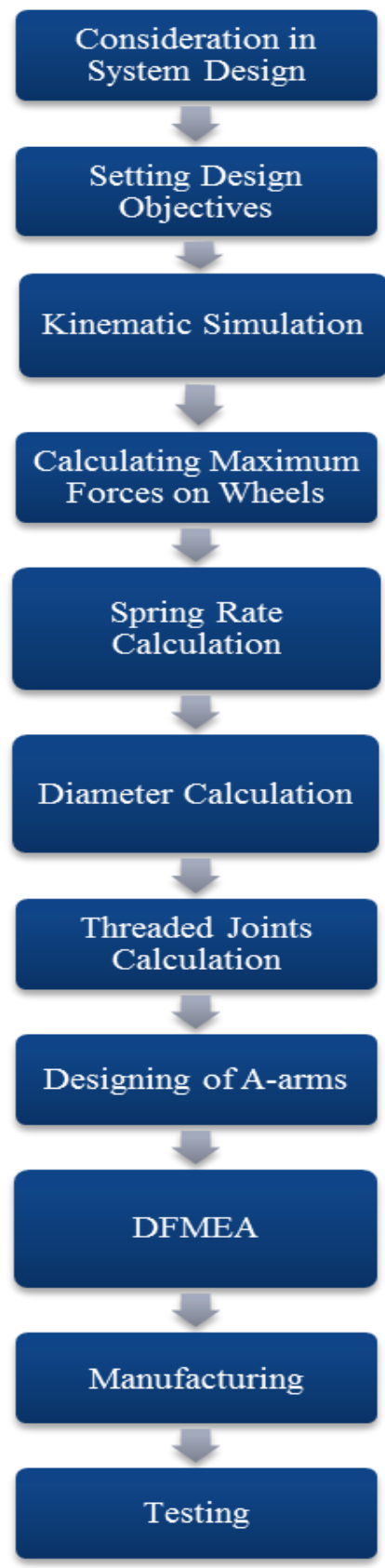

Fig3. Design Flowchart 


\section{DESIGN PHILOSOPHY}

Choosing suspension geometries and components involves a wide range of choices and compromises. An analysis of the tire, suspension component, chassis, and road interaction is required to decide the trade-offs that will result in an optimum configuration for the type of vehicle.

The necessary steps in designing a vehicle's suspension are:

- Selection of the suspension type to be employed;

- Selection of the wheels;

- Establish the vehicle's dimensions: wheelbase and track width(s);

- Model the suspension geometry;

- Designing components.

TABLE I. KINEMATIC SIMULATIONS

\begin{tabular}{|l|l|l|}
\hline Parameter & Front & Rear \\
\hline Scrub Radius & $56 \mathrm{~mm}$ & $70 \mathrm{~mm}$ \\
\hline Caster Trail & $12.64 \mathrm{~mm}$ & $0 \mathrm{~mm}$ \\
\hline Roll Rate & $132 \mathrm{Nm} / \mathrm{deg}$ & $124 \mathrm{Nm} / \mathrm{deg}$ \\
\hline Bump Coefficient & $0.083 \mathrm{deg} / \mathrm{mm}$ & $0.093 \mathrm{deg} / \mathrm{mm}$ \\
\hline Roll Gradient & $0.43 \mathrm{deg} / \mathrm{g}$ & $0.43 \mathrm{deg} / \mathrm{g}$ \\
\hline Wheel Rate & $15.22 \mathrm{~N} / \mathrm{mm}$ & $11.73 \mathrm{~N} / \mathrm{mm}$ \\
\hline Jounce & $30 \mathrm{~mm}$ & $30 \mathrm{~mm}$ \\
\hline Rebound & $30 \mathrm{~mm}$ & $30 \mathrm{~mm}$ \\
\hline
\end{tabular}

TABLE II. VEHICLE PARAMETERS

\begin{tabular}{|l|l|}
\hline Parameter & Value (in mm) \\
\hline Wheelbase & 1545 \\
\hline Track (front) & 1000 \\
\hline Track (rear) & 1100 \\
\hline Static camber & $-2^{\circ}$ \\
\hline Castor & $4^{\circ}$ \\
\hline Static toe & $2^{\text {o }}$ (in) \\
\hline Kingpin angle (front) & $4^{\text {o }}$ \\
\hline Kingpin angle (rear) & $0^{\circ}$ \\
\hline Roll center height (front) & 7.42 \\
\hline Roll center height (rear) & 32.55 \\
\hline Static weight distribution & $45: 55$ \\
\hline
\end{tabular}

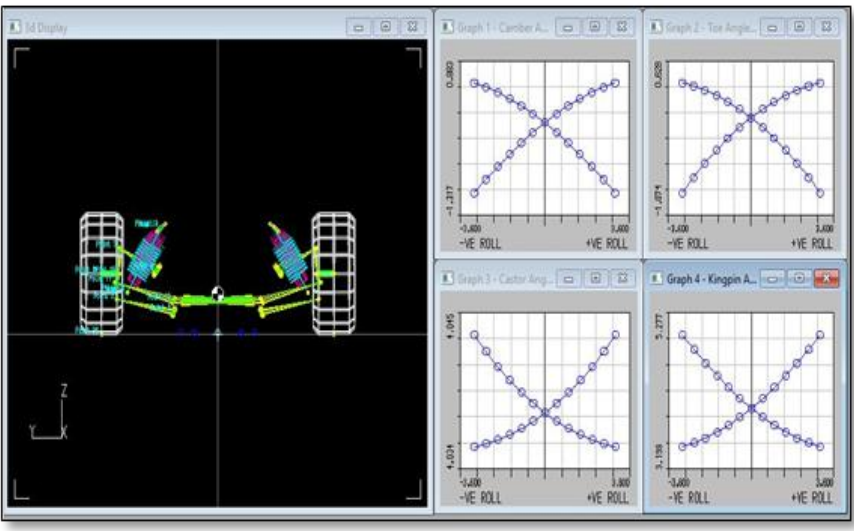

Fig4. Lotus simulation in roll condition

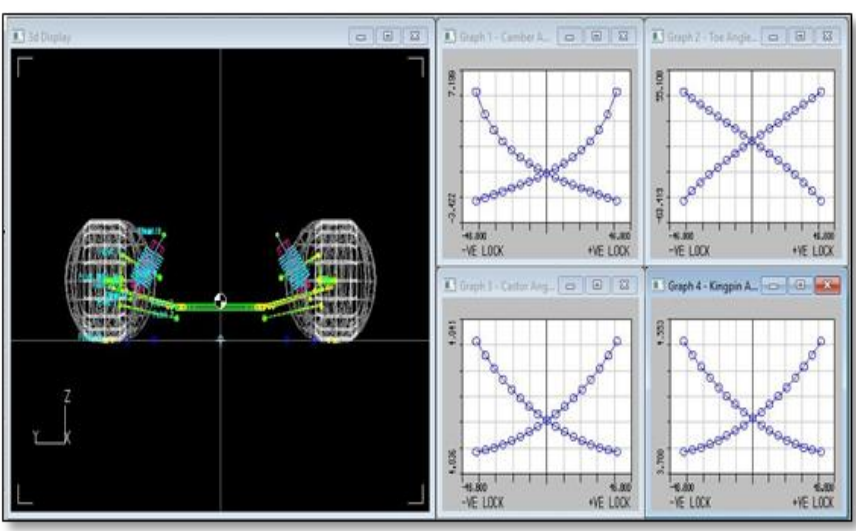

Fig5. Lotus simulation in steer condition

VII Load Transfer

The inertia of a mass is its resistance to change its state. For the change of state of a body, it must experience acceleration in its motion direction. Acceleration, braking, or cornering is nothing but the change of state of the vehicle, which offers resistance for a while and results in load transfer in a direction opposite to the force causing the change. No doubt, this load transfer persists for a short duration of time, but its impact on the car's performance is much more crucial.

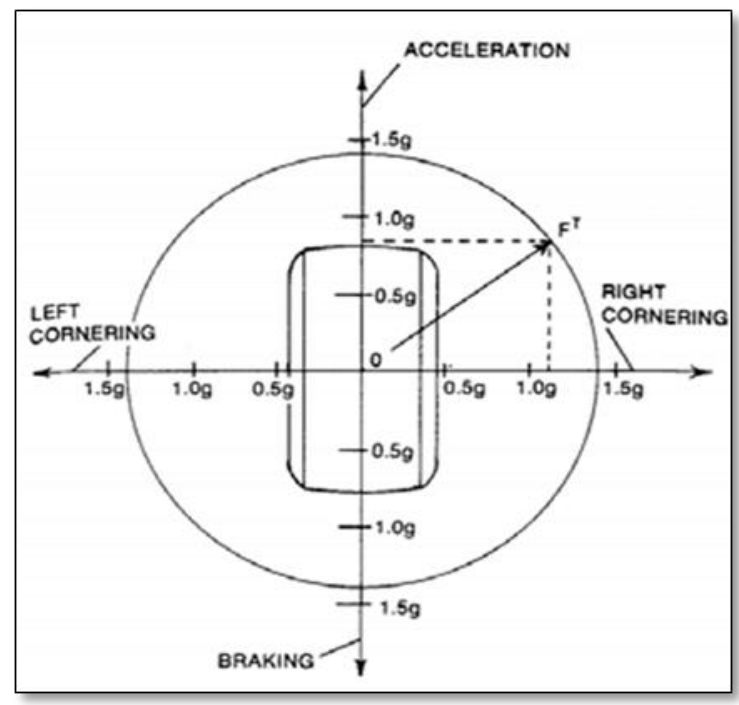

Fig6. Traction Circle 
The max longitudinal acceleration $\mathrm{Ax}=1.2 \mathrm{~g}$

The max lateral acceleration $\mathrm{Ay}=1.4 \mathrm{~g}$

However, the maximum acceleration experienced by the vehicle is during cornering accompanied by braking and given by:

$\sqrt{ } 1.2^{2}+1.4^{2}=1.84 \mathrm{~g}$

Thus, maximum acceleration $=1.84 \mathrm{~g}$

Now, the weight of the car is $250 \mathrm{kgs}$.

$\mathrm{W}_{\mathrm{f}}: \mathrm{W}_{\mathrm{r}}=45: 55$

$\therefore \mathrm{W}_{\mathrm{f}}=112.5 \mathrm{~kg}=1103.62 \mathrm{~N}$

$\therefore \mathrm{W}_{\mathrm{r}}=137.5 \mathrm{~kg}=1348.87 \mathrm{~N}$.

Weight on single wheels in steady-state is:

$\mathrm{W}_{\mathrm{f} \text { (single) }}=56.25 \mathrm{~kg}=551.81 \mathrm{~N}$

$\mathrm{W}_{\mathrm{r} \text { (single) }}=68.75 \mathrm{~kg}=674.43 \mathrm{~N}$

The total longitudinal load transfer can be calculated as

$\Delta \mathrm{W}_{\text {longitudinal }}=\left(\mathrm{W} * \mathrm{H}_{\mathrm{CG}} * \mathrm{Ax}\right) /$ wheelbase

$\Delta \mathrm{W}_{\text {longitudinal }}=(250 * 135 * 1.2) / 1545$

$\Delta \mathbf{W}_{\text {longitudinal }}=26.21 \mathrm{~kg}=257.15 \mathrm{~N}$

The total lateral load transfer can be calculated as

$\Delta \mathrm{W}_{\text {lateral }}=\left(\mathrm{W}^{*} \mathrm{H}_{\mathrm{CG}} * \mathrm{Ay}\right) /$ trackwidth

$\Delta \mathrm{W}_{\text {lateral }}=(250 * 135 * 1.4) / 1000$

$\Delta W_{\text {lateral }}=47.25 \mathrm{~kg}=463.52 \mathrm{~N}$

However, the max load transfer can occur during cornering and braking. This will be the diagonal load transfer on the front outer wheel.

$$
\begin{aligned}
& \Delta \mathrm{W}_{\text {diagonal }}=\sqrt{ }\left(\Delta \mathrm{W}_{\text {longitudina }} \mathrm{l}^{2}+\Delta \mathrm{W}_{\text {lateral }^{2}}\right) \\
& \Delta \mathrm{W}_{\text {diagonal }}=\sqrt{ }\left(26.21^{2}+47.25^{2}\right) \\
& \Delta \mathbf{W}_{\text {diagonal }}=54.03 \mathrm{~kg}=530.06 \mathrm{~N}
\end{aligned}
$$

Thus, the maximum load on a single wheel is:

$\Delta \mathrm{W}_{\max }=\mathrm{W}_{\mathrm{f} \text { (single) }}+\Delta \mathrm{W}_{\text {diagonal }}$

$\Delta W_{\max }=110.28 \mathrm{kgs}=1081.84 \mathrm{~N}$

\section{Front spring \\ VIII SPRING RATES}

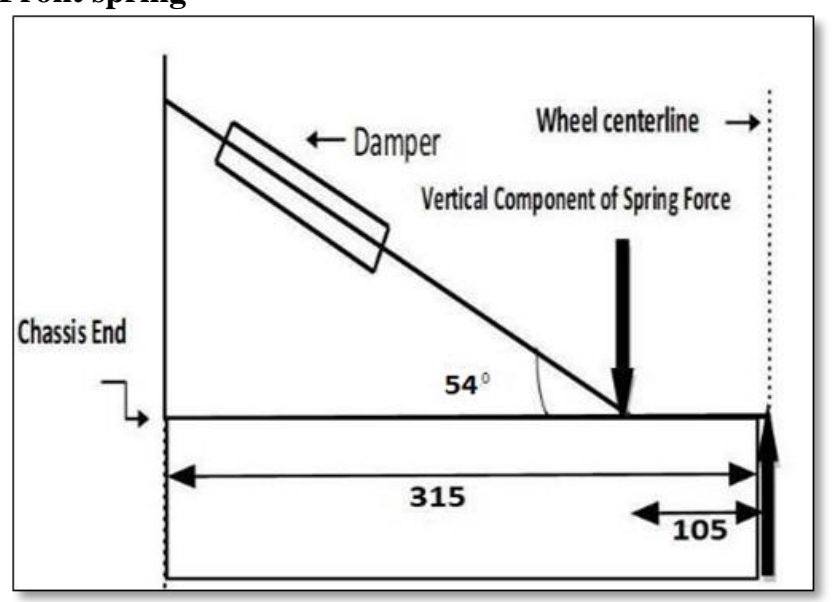

Fig7. Free Body Diagram
Sprung mass $=250 \mathrm{~kg}$ (approx.)

The factor for static to dynamic conditions: 2.1

According to the mass distribution of 55:45 (Rear: Front)

Mass per wheel (Front) $=56.25 \mathrm{~kg}$

Angle of inclination of the strut $=54$ (from horizontal)

Point of attachment of strut $=210 \mathrm{~mm}$ from chassis end (from suspension geometry)

Reaction force acting from the ground on the wheel=

$(56.25 \mathrm{~kg} * 9.81) \mathrm{N}=551.8125$

Considering the A-arm hinges (A) as the point about which moment is taken;

The horizontal distance of reaction force from hinge point $=$ $315 \mathrm{~mm}$ from suspension geometry

The horizontal distance of strut attachment point from hinge point $=210 \mathrm{~mm}$

By taking moment about hinge points:

$551.81 * 315=$ Spring Force $* \sin 54 * 210$

Spring Force $=1023.11 \mathrm{~N}$

Considering the dynamic factor,

Dynamic force acting on the spring $=2046.22 \mathrm{~N}$

Hence,

Spring Stiffness = Dynamic Spring Force $/$ Deflection

$$
\begin{aligned}
& =2046.22 / 55.8 \\
& =36.67 \mathrm{~N} / \mathrm{mm} \approx 37 \mathrm{~N} / \mathrm{mm}
\end{aligned}
$$

By using a similar procedure,

\section{For Rear}

Spring Force $=1384.98 \mathrm{~N}$

Dynamic Force acting on spring $=2285.22$

Spring Stiffness $=40.8 \mathrm{~N} / \mathrm{mm}$

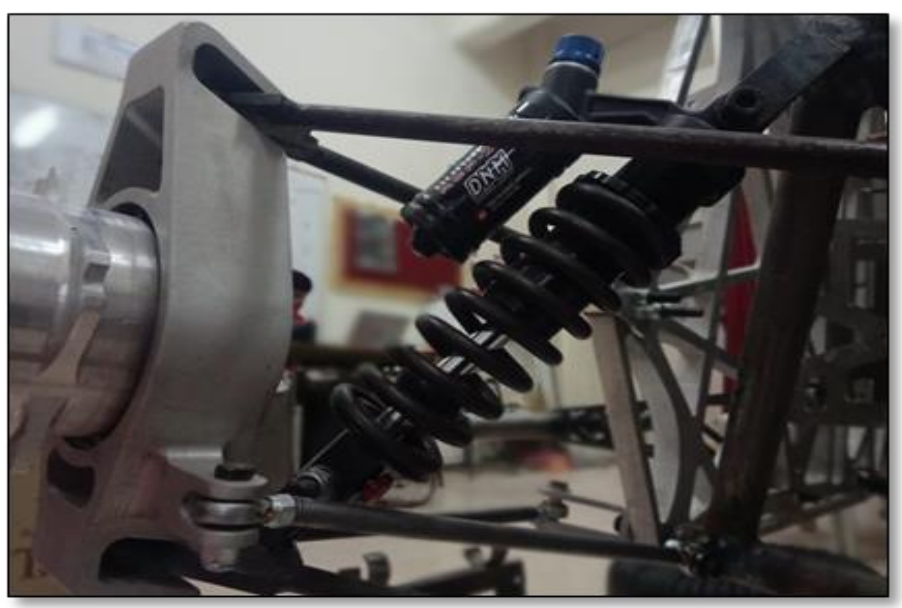

Fig8. Double wishbone suspension system on car 


\section{DESIGN OF A-ARM}

As calculated above, the maximum forces on the wheels are:

\section{A. For Front}

$\mathrm{F}_{\mathrm{z}}=110.28 * 9.81=\mathbf{1 0 8 1 . 8 4} \mathbf{N}$

$\mathrm{F}_{\mathrm{x}}=1.2 * 9.81 *(56.25+13.10)=816.388 \mathrm{~N}$

Force on single A arm $=816.388 / 2=408.19 \mathbf{~ N}$

$\mathrm{F}_{\mathrm{y}}=1.4 * 9.81 *(56.25+23.62)=1096.93 \mathrm{~N}$

Force on single A arm $=1096.93 / 2=\mathbf{5 4 8 . 4 6} \mathbf{N}$

Calculated - Spring Force $=\mathbf{1 0 2 3 . 1 1} \mathbf{N}$.

The analytical calculation for:

Threaded Joints

$\mathrm{P}_{\mathrm{act}}=\sqrt{ }\left[\left(\mathrm{F}_{\mathrm{x}}^{2}+\mathrm{F}_{\mathrm{y}}^{2}+\mathrm{F}_{\mathrm{z}}^{2}\right)^{2}+(\text { spring force })^{2}\right]$

$P_{\text {act }}=\sqrt{1279.76^{2}+1023.11^{2}=1638.45 \mathrm{~N}}$

(18)

$\mathrm{S}_{\mathrm{yt}}=215 \mathrm{MPa}$ FOS $=2$

For permissible tensile stress

$\sigma_{t}=\mathrm{S}_{\mathrm{yt}} / \mathrm{FOS}=215 / 2=107.5 \mathrm{~N} / \mathrm{mm}^{2}$

(19)

$\sigma_{t}=\mathrm{P}_{\mathrm{act}} /\left[(\pi / 4) * \mathrm{~d}_{\mathrm{c}}^{2}\right]$

(20)

Now, $\mathrm{d}_{\mathrm{c}}=\sqrt{ }\left[\left(\mathrm{P}_{\mathrm{act}} * 4\right) / \pi * \sigma_{t}\right]=4.40 \mathrm{~mm}$

(21)

$\mathrm{d}=4.40 / 0.8=5.5 \mathrm{~mm}[(\mathrm{~h}=0.8 \mathrm{~d})$ the factor determining threads will not fail in shear.]

$\mathrm{d}=5.5 \approx 6 \mathrm{~mm}$

\begin{tabular}{|c|c|c|c|c|c|c|}
\hline \multirow[t]{2}{*}{ Designation } & \multirow{2}{*}{$\begin{array}{c}\text { Nominal or major } \\
\text { diadD } \\
(\mathrm{mm})\end{array}$} & \multirow{2}{*}{$\begin{array}{c}\text { Pich (p) } \\
(\mathrm{mm})\end{array}$} & \multirow{2}{*}{$\begin{array}{c}\text { Pitch diameter } \\
d_{p} D_{p} \\
(m m)\end{array}$} & \multicolumn{2}{|c|}{ Minor diameter } & \multirow{2}{*}{$\begin{array}{c}\text { Tensilestress } \\
\text { area } \\
\left(\mathrm{mm}^{2}\right)\end{array}$} \\
\hline & & & & & & \\
\hline$M 6 \times 1$ & 6 & 1.00 & 5.350 & 4.773 & 4.917 & 20.1 \\
\hline M $6 \times 0.75$ & 6 & 0.75 & 5.513 & 5.080 & 5.188 & 22.0 \\
\hline$M 8 \times 1.25$ & 8 & 1.25 & 7.188 & 6.466 & 6.647 & 36.6 \\
\hline$M 8 \times 1$ & 8 & 1.00 & 7.350 & 6.773 & 6.917 & 39.2 \\
\hline M $10 \times 1.25$ & 10 & 1.25 & 9.188 & 8.466 & 8.647 & 61.2 \\
\hline M 10x1 & 10 & 1.00 & 9.350 & 8.773 & 8.917 & 64.5 \\
\hline
\end{tabular}

Fig9. Basic dimensions of screw threads (fine series)

- $\quad$ Fine threads are used where the parts are subjected to dynamic load and vibration.

- Hollow thin-walled parts where coarse threads are liable to weaken the wall considerably

- These are used in parts which are used for the purpose of adjustment.

Hence from the standard reference table of fine series, we have chosen M6 x 1

Accordingly, the POS 6 rod end was selected.
Considering this as the inner diameter, the outer diameter was calculated by the following procedure:

\section{Analytical Calculation for diameter calculation:}

\section{For Front}

FOS $=\mathrm{P}_{\mathrm{cr}} / \mathrm{P}_{\mathrm{act}}$

$\mathrm{P}_{\mathrm{cr}}=\left(\pi^{2} \mathrm{EI}\right) /(\mathrm{KL})^{2} \quad(\mathrm{~K}=2$ Because the condition

is one end fixed, other free)

$\left(\mathrm{FOS} *(\mathrm{KL}){ }^{2 *} \mathrm{P}_{\mathrm{act}}\right) / \pi^{2} * \mathrm{E}=(\pi / 64) *\left(\mathrm{do}^{4}-\mathrm{di}^{4}\right)$

$\mathrm{E}=205^{*} 10^{3} \mathrm{MPa}$

\begin{tabular}{|l|c|c|}
\hline Mechanical Properties & Metric & English \\
\hline Hardness, Vickers & 170 & 170 \\
\hline Ultimate tensile strength & $440 \mathrm{MPa}$ & $63800 \mathrm{psi}$ \\
\hline Yield strength & $370 \mathrm{MPa}$ & $53700 \mathrm{psi}$ \\
\hline Modulus of Elasticity & $205 \mathrm{GPa}$ & $29700 \mathrm{ksi}$ \\
\hline Bulk Modulus & $140 \mathrm{GPa}$ & $20300 \mathrm{ksi}$ \\
\hline Shear Modulus & $80 \mathrm{GPa}$ & $11600 \mathrm{ksi}$ \\
\hline Machinability & $78 \%$ & $78 \%$ \\
\hline
\end{tabular}

(Source: www.matweb.com; ASM International, 1990)

Fig10. Mechanical properties of AISI 1018 steel

$$
\begin{aligned}
& \left(2 *(2 * 210)^{2 *} 1638.45^{*} 64\right) /\left(\pi^{2 *} 205^{*} 10^{3 *} \pi\right)=\mathrm{do}^{4}-\mathrm{di}^{4} \\
& \text { Considering } \mathbf{d}_{\mathbf{i}}=\mathbf{6} \mathbf{m m} \\
& \mathbf{d}_{\mathbf{0}}=\mathbf{9 . 1 8} \approx \mathbf{1 0} \mathbf{~} \mathbf{~ m}
\end{aligned}
$$

\begin{tabular}{|c|c|c|c|}
\hline$R 5$ & $R 10$ & $R 20$ & $R 40$ \\
\hline 1.00 & 1.00 & 1.00 & 1.00 \\
& & & 1.06 \\
& & 1.12 & 1.12 \\
& & & 1.18 \\
& & 1.25 & 1.25 \\
& & & 1.32 \\
& & 1.40 & 1.40 \\
& & & 1.50 \\
\hline
\end{tabular}

Fig11.1. Preferred series 


\begin{tabular}{|l|l|l|l|}
\hline 1.60 & 1.60 & 1.60 & 1.60 \\
& & & 1.70 \\
& & 1.80 & 1.80 \\
& & & 1.90 \\
& 2.00 & 2.00 & 2.00 \\
& & & 2.12 \\
& & 2.24 & 2.24 \\
2.50 & \multirow{2}{*}{2.50} & 2.50 & 2.36 \\
& & & 2.65 \\
\hline
\end{tabular}

Fig11.2. Preferred series

By using the preferred series R5 which is $1,1.6,2.5,4,6.30,8,10$, the diameter 10 was selected.

Hence, $\mathrm{d}_{\mathrm{o}}=9.18 \approx 10 \mathrm{~mm}$

Accordingly, an A-arm endplate was designed. To accommodate the spherical bearing, a bush (with accurate tolerance) was inserted in the laser cut part. This ensured proper fitment of the spherical bearing.

Slots on the laser cut part ensured accurate positioning of the damper mounts.

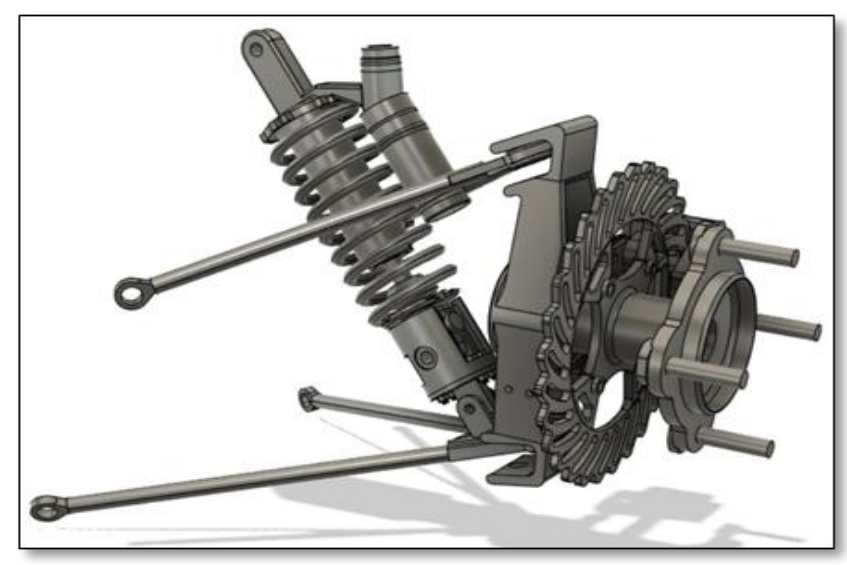

Fig12. Suspension Assembly

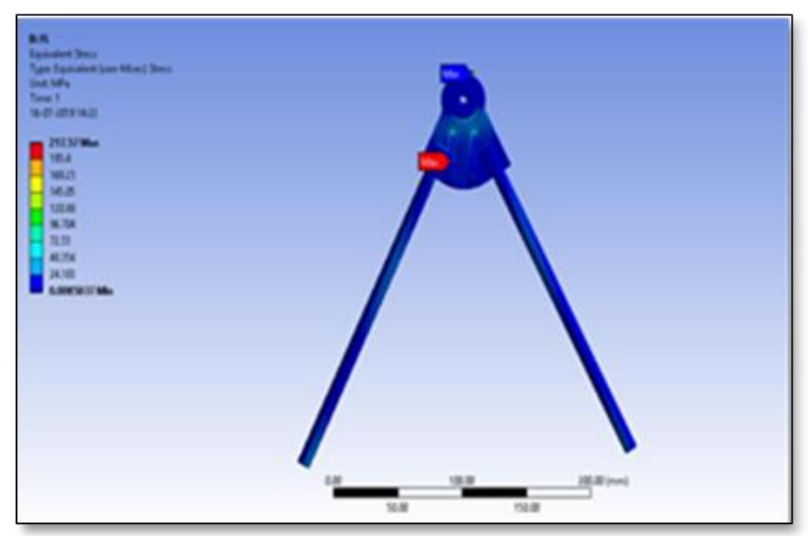

Fig13. Max Von-Misses stress $=217.57 \mathrm{MPa}$

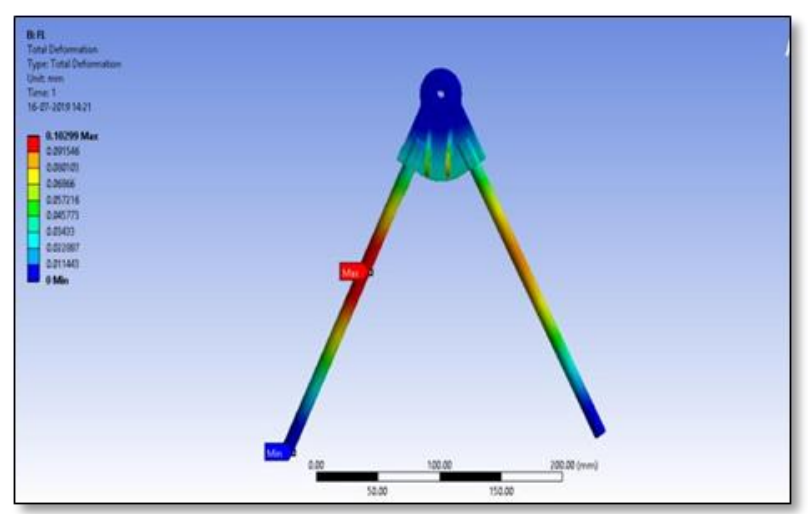

Fig14. Max deformation $=0.102 \mathrm{~mm}$

\section{CONCLUSION}

The purpose of this paper was to find the diameter of the double-wishbone by analytical calculations. The force is calculated using basic concepts. This paper gives a clear idea of how the forces are taken into consideration. Material is selected based upon calculated forces. Double-wishbone is designed using suspension points and dynamic force applied considering the factor of safety. Design is validated by using Ansys 16.0 software. This design is fabricated and tested in the Formula Student race car in all dynamic conditions. No failure occurred at the time of testing, it can be concluded that forces calculations and design are up to the mark.

\section{ACKNOWLEDGMENT}

We would also like to thank Team Redline Racing for successfully designing and manufacturing the Formula Student race car. 


\section{REFERENCES}

[1] William F.Miliken, Doughlas L.Miliken.1995.Race Car Vehicle Dynamics Volume 146 of R.: Society of Automotive Engineers, SAE International

[2] Thomas D. Gillespie, Fundamentals of Vehicle Dynamics (Society of Automotive Engineers)

[3] Bhandari V.B. 'Design of Machine Elements' 2014, McGraw Hill Education(India)

[4] Supra SAEINDIA 2019 rulebook.

[5] Shaikh Vasim.A 'Mist and Microstructure characterization in end milling AISI1018' August 2013,

[Online] Available: https://www.researchgate.net/publication/307988801

[6] Bansal.R.K ‘A Textbook of Strength of Materials’ 2010, Laxmi Publications

\section{AUTHORS}

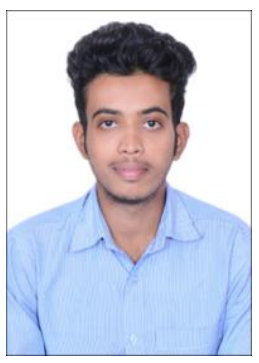

Suyash Yashwant Wagh completed Bachelor of Engineering in Mechanical Engineering from the JSPM's Rajarshi Shahu College of Engineering affiliated to Pune University, India. His research interests in the field of vehicle dynamics and completed certification training in MSC Adams simulation software.

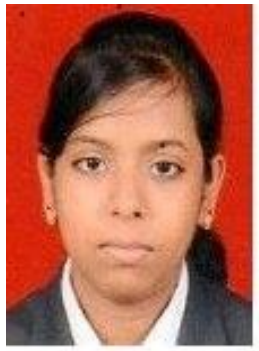

Eshita Amal Nandi is currently in the final year of Bachelors of Engineering in Mechanical Engineering from the JSPM's Rajarshi Shahu College of Engineering affiliated to Pune University, India. Her research interests include in the field of analytical research, vehicle dynamics and simulation software. 